\title{
Electrochemically Deposited Calcium Phosphate Coatings Using a Potentiostat of In-house Design and Implementation
}

\author{
F. N. Jiménez-García ${ }^{a, b *}$ (), L.R. Giraldo-Torres ${ }^{a} \mathbb{C}^{\mathbb{C}, \text { E. Restrepo-Parra }}{ }^{b}$ \\ ${ }^{a}$ Universidad Autónoma de Manizales, Departamento de Física y Matemática, Manizales, 17004, \\ Colombia. \\ ${ }^{b}$ Universidad Nacional de Colombia Sede Manizales, Facultad de Ciencias Exactas y Naturales, \\ Departamento de Física y Química, 17004, Colombia.
}

Received: February 22, 2021; Revised: June 28, 2021; Accepted: July 24, 2021

\begin{abstract}
The effect of growth conditions and post treatments on the properties of calcium phosphate films electrodeposited by a potentiostat of the authors' design and construction is presented. The electrolyte used was formed with $0.025 \mathrm{M}\left(\mathrm{NH}_{4}\right) \mathrm{H}_{2} \mathrm{PO}_{4}$ and $0.042 \mathrm{M} \mathrm{Ca}\left(\mathrm{NO}_{3}\right)_{2} .4 \mathrm{H}_{2} \mathrm{O}$, and its $\mathrm{pH}$ was kept at 5 . A voltametric analysis was performed to determine the necessary potential values to obtain the films. Additionally, the temperature of the electrolyte was varied to determine its influence on the properties of the deposited films. The films were characterized by Fourier transform infrared spectroscopy, X-ray diffraction and scanning electron microscopy. The films deposited at $-1.4 \mathrm{~V}$ and $-1.7 \mathrm{~V}$ present the brushite phase. The thermal post-treatment favored the formation of octagonal calcium phosphate in amorphous phase, while the basic treatment provided the $\mathrm{OH}$ - groups necessary for the formation of hydroxyapatite. The low cost potentiostat implemented presents excellent characteristics for obtaining films with similar characteristics to those obtained with a conventional potentiostat.
\end{abstract}

Keywords: Calcium phosphate, electrodeposition, potentiostat, basic treatment, thermal treatment.

\section{Introduction}

To improve the biological performance and biocompatibility of metallic implants, some biocompatible materials coatings have been applied to the substrates, especially, calcium phosphate $(\mathrm{CaP})$ biomaterials. CaP compounds have biological significance and mainly include a variety of phases depending on the concentration of calcium and phosphate ions $\left(\mathrm{Ca}^{2+}\right.$ and $\left.\mathrm{PO}_{4}{ }^{3-}\right)$, for example, the most common $\mathrm{CaP}$ phases are brushite and hydroxyapatite $\mathrm{e}^{1,2,3,4}$.

To obtain CaP films, techniques such as plasma spraying $^{5,6,7}$, biomimetic deposition ${ }^{8,9}$, sol-gel ${ }^{10,11,12}$, electrodeposition ${ }^{13,14,15}$ have been employed. CaP synthesis methods and their parameters, such as grade of crystallization, particle size, phase's composition, thermal stability, microstructure, and mechanical properties, can significantly impact stoichiometry of the product ${ }^{13,15}$.

The electrodeposition technique has been extremely attractive for several research groups due to its versatility, ease of implementation and low $\cos ^{16,17,18}$. Recently, research interest has evolved in the electrodeposition technique since this technique holds the potential to achieve crystalline deposits even at low temperatures. In this technique, some important parameters to be controlled are temperature of synthesis, $\mathrm{pH}$ of the precursor solution, reagent type and concentration, purity and quality of raw materials, and electrical conditions ${ }^{19,20,21}$. The electrodeposition process is done mainly in two ways, with variations on current density or with variations in voltage. Current density variations oscillate

*e-mail: francy@autonoma.edu.co between 0.5 and 2.5 to $3 \mathrm{~mA} / \mathrm{cm}^{2}$ 17,18. Voltage variations can also be achieved in two ways, by cyclic voltammetry and by constant potential. The first has scanning potentials ranging from 0 to -1.6 or $-2.5 \mathrm{~V} / \mathrm{SCE}^{2,16}$; and in the second, cathode potential is mostly negative in such values as $-1.4 \mathrm{~V} / \mathrm{SCE}$ and $-2.5 \mathrm{~V} / \mathrm{SCE}^{16}$. The temperature has been also modified by some authors to values from $6^{\circ} \mathrm{C}^{2}$ to $85^{\circ} \mathrm{C}^{16,18}$. The optimal conditions reported are $50^{\circ} \mathrm{C}^{2}$ and $70^{\circ} \mathrm{C}^{16}$.

When precipitated from aqueous solutions of low saturation, and under certain conditions, such as in electrodeposition technique, some phases can be formed: Dicalcium Phosphate Dihydrate $\left(\mathrm{CaHPO}_{4} \cdot 2 \mathrm{H}_{2} \mathrm{O}, \mathrm{DCPD}\right.$ - also called brushite, $\mathrm{Ca} / \mathrm{P}=1.00)$; Octacalcium Phosphate $\left(\mathrm{Ca}_{8} \mathrm{H}_{2}\left(\mathrm{PO}_{4}\right)_{6} .5 \mathrm{H}_{2} \mathrm{O}, \mathrm{OCP}\right.$, $\mathrm{Ca} / \mathrm{P}=1.33)$; Amorphous Calcium Phosphate $\left(\mathrm{Ca}_{9}\left(\mathrm{PO}_{4}\right)_{6} \cdot \mathrm{nH}_{2} \mathrm{O}\right.$, $\mathrm{ACP}, \mathrm{Ca} / \mathrm{P}=1.50)$; and Hydroxyapatite $\left(\left(\mathrm{Ca}_{10}\left(\mathrm{PO}_{4}\right)_{6}(\mathrm{OH})_{2}\right.\right.$, $\mathrm{HAp}, \mathrm{Ca} / \mathrm{P}=1.67)^{22}$. There are reports about the HAp coating preparation by electrodeposition method ${ }^{23,24}$ but in some cases, the HAp is not obtained immediately ${ }^{24,25}$. In this sense, brushite and octacalcium phosphate, that precipitate rapidly from solution, act as a precursor phase for $\mathrm{HAp}^{25}$, but submitting these films to some post treatment to achieve de HAp phase is necessary.

To obtain the CaP films, the electrodeposition technique was used by employing a potentiostat of the authors' design and implementation. This potentiostat presents several features that are worth highlighting: its low cost, the possibility of interacting with the software since it has been developed by the authors, and the reproducibility of the experiments. In this work there is evidence that the coatings obtained have characteristics 
comparable to those obtained with a conventional potentiostat $t^{2,26}$. In addition, it has been found that it is sufficient to electrodeposit the brushite phase films at room temperature, and then perform a basic treatment to obtain the HAp phase.

The parameters that were varied to obtain the films were the following: the working potential, the temperature of the electrolytic solution, and the post treatment processes. The post-treatments, thermal process, and basic process were performed in order to identify the first stages of the formation of the HAp phase, which some authors have reported $^{27,28}$. The composition, structure and morphology of the $\mathrm{CaP}$ coatings were obtained by Fourier Transform Infrared Spectroscopy (FTIR), X-Ray Diffraction (XRD) and Scanning Electron Microscopy (SEM) equipped with energy dispersive spectroscopy (EDS).

\section{Experimental Setup and Procedure}

In this section, the experimental details are provided divided into three subsections: materials employed, synthesis process and characterization.

\subsection{Materials}

Sheets $(20 \mathrm{~mm} \times 10 \mathrm{~mm} \times 1 \mathrm{~mm})$ of $316 \mathrm{~L}$ stainless steel having composition (wt.\%) C 0.0190, N 0.0661, Si 0.553, P 0.021, V 0.078, Cr 17.09, Mn 1.672, Co 0.134, Ni 11.65, $\mathrm{Cu} 0.232$, Mo 0.531, Ti 0.005, and Fe 65.95, were used as the cathode. Prior to use, all the substrates were polished with silicon carbide papers of up to 1500 grit and the final polishing was done with alumina and fine diamond pastes to produce scratch-free mirror finish surface. Then, sheets were cleaned and degreased with acetone-ethanol solution in a 1:1 volume ration, rinsed successively by distilled water, air dried, and stored for further electrodeposition.

The electrolyte solution was prepared by dissolving analytical grades of $\left(\mathrm{NH}_{4}\right) \mathrm{H}_{2} \mathrm{PO}_{4}$ and $\mathrm{Ca}\left(\mathrm{NO}_{3}\right)_{2} 4 \mathrm{H}_{2} \mathrm{O}$ (Panreac $96 \%$ ) in deionized water under gentle magnetic stirring, with the $\mathrm{Ca} / \mathrm{P}$ ratio being 1.67 ; the $\mathrm{pH}$ was adjusted by adding $1 \mathrm{M}$ of ammonia solution at $\mathrm{pH}=5$. The solution concentration was $0.025 \mathrm{M}\left(\mathrm{NH}_{4}\right) \mathrm{H}_{2} \mathrm{PO}_{4}$ and $0.042 \mathrm{M} \mathrm{Ca}\left(\mathrm{NO}_{3}\right)_{2} 4 \mathrm{H}_{2} \mathrm{O}$. Those values were determined from previous results where a conventional potentiostat was employed ${ }^{26}$.

\subsection{Synthesis}

The electrodeposition process was developed in a potentiostat and in a three-electrode cell of the authors' design and implementation as previously reported ${ }^{26}$. The configuration of the three-electrode cell is the following: a stainless-steel specimen served as the cathode while platinum acted as the anode, and the $\mathrm{Ag} / \mathrm{AgCl}$ as the reference electrode. Constant cathodic potentials were applied using a potentiostat developed in the authors' laboratory (potentials of $\pm 20 \mathrm{~V}$, resolution $1 \mu \mathrm{V}$, and currents of $\pm 2 \mathrm{~A})^{29}$. To determine the reduction potential of the reaction that occurs at the $316 \mathrm{~L}$ stainless steel electrode a cyclic voltammetric method with a potential between 5 and $-5 \mathrm{~V} / \mathrm{SCE}$, and scan rate of $100 \mathrm{mV} / \mathrm{s}$ was used.

The process was carried out for 30 minutes in potentiostatic mode, and the distance between the electrodes was $2 \mathrm{~cm}$. It is important to note that this potentiostatic mode was developed for the designed potentiostat. The deposition process was conducted from room temperature to $60^{\circ} \mathrm{C}$ increasing 10 degrees each time (i.e., 20, 30, 40, 50 and $60{ }^{\circ} \mathrm{C}$ ). A higher temperature was not used because of the character of the aqueous solution and because the reference electrode is damaged above $80^{\circ} \mathrm{C}$. After electrodeposition, the substrates coated with calcium phosphate films were gently rinsed in deionized water and dried in an air stream.

After deposition, two further treatments were used according to literature reports. The thermal treatment (TT) was carried out by applying a heating ramp at a rate of $3 \%$ min until a temperature of $600{ }^{\circ} \mathrm{C}$ was reached; this temperature was then held for two hours in the atmosphere and finally allowed to $\mathrm{cool}^{30}$. The basic treatment (BT) was carried out during $1 \mathrm{~h}$ at $80^{\circ} \mathrm{C}$ in a $1 \mathrm{M}$ $\mathrm{NaOH}$ solution as some authors have reported ${ }^{31}$. Then, the films were gently washed in distilled water and dried in an air current. A schematic representation of the process is shown in Figure 1 The index for deposited coatings is shown in Table 1.

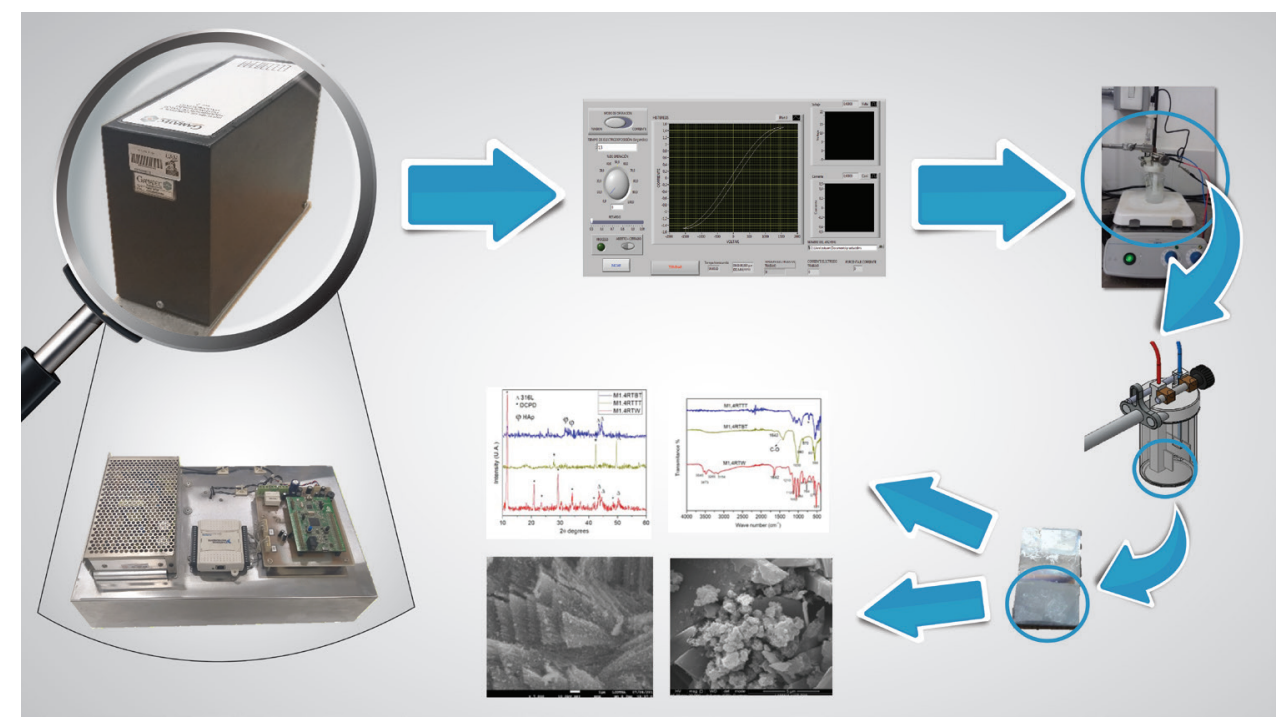

Figure 1. Schematic representation of the process. 
Table 1. Index for deposited coating.

\begin{tabular}{cccc}
\hline Sample & $\begin{array}{c}\text { Solution } \\
\text { temperature }\end{array}$ & Post treatment & $\begin{array}{c}\text { Growing } \\
\text { potential }\end{array}$ \\
\hline M1,4RTW & $\begin{array}{c}\text { Room } \\
\text { temperature }\end{array}$ & Without & $-1.4 \mathrm{~V}$ \\
\hline M1,4RTTT & $\begin{array}{c}\text { Room } \\
\text { temperature }\end{array}$ & Thermal & $-1.4 \mathrm{~V}$ \\
\hline M1,4RTBT & $\begin{array}{c}\text { Room } \\
\text { temperature }\end{array}$ & Basic & $-1.4 \mathrm{~V}$ \\
\hline M1,7RTW & $\begin{array}{c}\text { Room } \\
\text { temperature }\end{array}$ & Without & $-1.7 \mathrm{~V}$ \\
\hline M1,7RTBT & $\begin{array}{c}\text { Room } \\
\text { temperature }\end{array}$ & Basic & $-1.7 \mathrm{~V}$ \\
\hline $\mathrm{M} 2,6 \mathrm{RTW}$ & $\begin{array}{c}\text { Room } \\
\text { temperature }\end{array}$ & Without & $-2.6 \mathrm{~V}$ \\
\hline $\mathrm{M} 1,4 T W *$ & $\mathrm{~T}=40^{\circ} \mathrm{C}$ & Without & $-1.4 \mathrm{~V}$ \\
\hline $\mathrm{M} 1,4 \mathrm{TBT}$ & $\mathrm{T}=40^{\circ} \mathrm{C}$ & Basic & $-1.4 \mathrm{~V}$ \\
\hline $\mathrm{N}$
\end{tabular}

Note: *A sample obtained in precursor solution at $40^{\circ} \mathrm{C}$ was selected; however, deposition was carried out at different temperatures: 20,30 , 40,50 and $60^{\circ} \mathrm{C}$

\subsection{Characterization}

Fourier Transform Infrared Spectra (FTIR) was used to identify the chemical bonding in the coatings. An Alpha Platinum ATR Bruker spectrophotometer was used to record the FTIR spectra in the range from 4000 to $400 \mathrm{~cm}^{-1}$, with a 32 scans, resolution of $4 \mathrm{~cm}^{-1}$, and laser Nd:Y $1064 \mathrm{~nm}$. $\mathrm{X}$-ray diffraction (XRD) using Bruker D-8 Advance-Germany Spectrometer, with $\mathrm{CuK} \alpha$ radiation $\lambda=1.5406 \AA$ generated at $35 \mathrm{kV}$ and $25 \mathrm{~mA}$, was employed to determine the phases of the coatings. Data were collected over the $2 \theta$ range $10-60^{\circ}$, and at grazing angles with a step size of $0.010^{\circ}$ and a count time of $0.2 \mathrm{~s}$. To identify the surface morphology and element composition of coatings, the scanning electron microscopy (SEM, Quanta-250, FEI) was used equipped with an energy dispersion spectroscopy (EDS) (GENESIS APEX2i) facility. Besides, a profilometer was used to measure the thickness of films, which varied from 4.1 to $4.9 \mu \mathrm{m}$ for as deposited, and to 1.8 to $2.8 \mu \mathrm{m}$ for the post treated.

\section{Results and Discussion}

Four aspects are presented in this results section: first, the work potential determination; second, the growth potential effect; third, the post treatments effect; and finally, the study of the electrolytic solution temperature effect.

\subsection{Work potential determination}

In the electrochemical process, the nature of the electrode reactions can be determined with the analysis of currentpotential curves. The cyclic voltammetry measurements and electrodeposition process were developed with the potentiostat of the authors' design and implementation. In this analysis, it was found that for positive potentials no favorable reaction for the apatite deposition occurs while for negative ones the coatings are formed. Figure 2 shows the cyclic voltammetry curves in the range of $0.0 \mathrm{~V}$ to $-5.0 \mathrm{~V}$ conducted five times. The transient stage may be divided into three periods. Initially, the current density increases slowly between $0.0 \mathrm{~V}$ and $-2.5 \mathrm{~V}$ indicating that the nucleation process on the

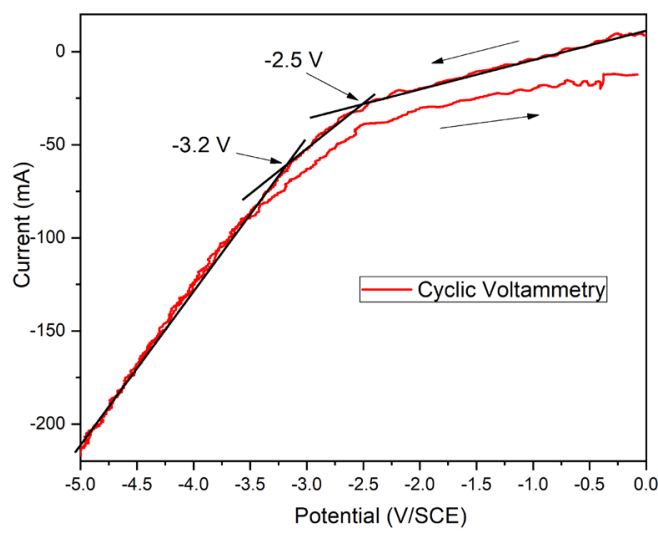

Figure 2. Cyclic voltammetry curve.

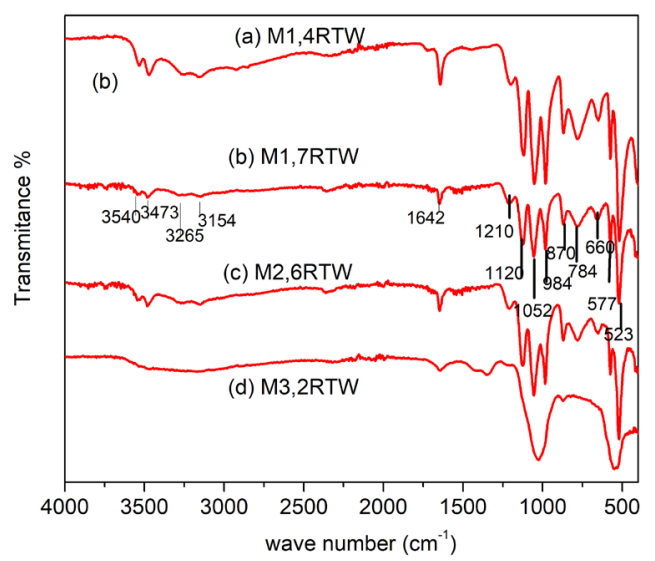

Figure 3. FTIR spectra for as deposited films growth at $-1.4 \mathrm{~V}$, $-1.7 \mathrm{~V}, 2.6 \mathrm{~V}$ and $-3.2 \mathrm{~V}$.

substrate surface is functioning. Films obtained at potential upper to $-1.4 \mathrm{~V}$ were not homogeneous. The second identified region is from $-2.5 \mathrm{~V}$ to $-3.2 \mathrm{~V}$ where the electrodeposition process continues with hydrogen burbling which begins at $-2.8 \mathrm{~V}$. Finally, a drastic increase of current occurs up to $-5 \mathrm{~V}$, and the burble in the electrode surface increase due to the evolution of $\mathrm{H}_{2}$. The range for the electrodeposition of calcium phosphates without interference of $\mathrm{H}_{2}$ evolution and with good adherences and homogeneity is between $-1.4 \mathrm{~V}$ and $-2.8 \mathrm{~V}$.

\subsection{Growth potential effect}

Films were grown in the range of $-1.4 \mathrm{~V}$ to $-3.2 \mathrm{~V}$ and analyzed by FTIR technique. Figure 3 shows the FTIR spectra for samples obtained at room temperature: M1,4RTW grown at $-1.4 \mathrm{~V}, \mathrm{M} 1,7 \mathrm{RTW}$ grown at $-1.7 \mathrm{~V}, \mathrm{M} 2,6 \mathrm{RTW}$ at $-2.6 \mathrm{~V}$ and M3,2RTW at $-3.2 \mathrm{~V}$, which showed the best homogeneity and adherence characteristics.

As can be seen in the FTIR spectra for films deposited at different potentials, two groups of bands are identified: one between $500 \mathrm{~cm}^{-1}$ and $600 \mathrm{~cm}^{-1}$ which are assigned to the asymmetric bending modes (O-P-O v4); the other between 
$1000 \mathrm{~cm}^{-1}$ and $1100 \mathrm{~cm}^{-1} 32$. These bands are characteristic of apatite and are associated with the asymmetric stretching vibration modes ( $\mathrm{P}-\mathrm{O} \mathrm{v} 3$ ) according to literature reports ${ }^{32}$. On the other hand, the band of about $980 \mathrm{~cm}^{-1}$ is associated with the symmetrical stretch vibration mode ( $\mathrm{P}-\mathrm{O} \mathrm{v} 1)$, and the one found at approximately $863 \mathrm{~cm}^{-1}$ is assigned to group vibration modes $\left(\mathrm{HPO}_{4} \mathrm{v} 5\right)$. There is also a band of approximately $3500 \mathrm{~cm}^{-1}$ which is assigned to vibration modes of adsorbed water stretching $\left(\mathrm{O}-\mathrm{H}-, \mathrm{H}_{2} \mathrm{O}\right)$, while the peak at $1642 \mathrm{~cm}^{-1}$ is associated to the bending mode $\mathrm{H}-\mathrm{O}-\mathrm{H}^{33}$.

Besides these general bands associated to apatite phases, some bands in 523, 577, 660, 784, 870, 984, 1052, 1120, 1210 , 1642 (H-O-H), 3154, 3265, 3473 and $3540 \mathrm{~cm}^{-1}$ associated with the DCPD phase are clearly identified for M1,4RTW, M1,7RTW and M2,6RTW films ${ }^{32}$. For the M3,2RTW film, the splitting bands at approximately $500 \mathrm{~cm}^{-1}$ and $1000 \mathrm{~cm}^{-1}$ do not appear, which indicates the formation of another phase. In the XRD patterns for this film (not shown here) the amorphous behavior is evident.

Since phosphate bands in $500 \mathrm{~cm}^{-1}$ and $1000 \mathrm{~cm}^{-1}$ are characteristic of the different apatite phases, the peak intensities for each phase differ from one to another. Thus, their intensity ratio was determined. It was found that, for $532 \mathrm{~cm}^{-1}$ and $1009 \mathrm{~cm}^{-1}$ bands, the intensities are the following: for M1,4RTW sample, $\mathrm{I} 1=0.30$ and $\mathrm{I} 2=0.21$ with a relation $\mathrm{I} 1 / \mathrm{I} 2=1.43$; for $\mathrm{M} 1,7 \mathrm{RTW}$ sample, $\mathrm{I} 1=0.18$ and $\mathrm{I} 2=0.11$ with a $\mathrm{I} 1 / \mathrm{I} 2=1.63$ relationship; and for $\mathrm{M} 2,6 \mathrm{RTW}$ sample, $\mathrm{I} 1=0.23$ and $\mathrm{I} 2=0.17$ with a $\mathrm{I} 1 / \mathrm{I} 2=1.35$ relationship. These values indicate that to obtain homogenous and adherent DCPD films, working in the $-1.4 \mathrm{~V}$ to $-2.8 \mathrm{~V}$ range where similar characteristics of films could be obtained is possible. This agrees with results presented previously in literature ${ }^{34}$ and in the authors' previous study carried out in a conventional potentiostat ${ }^{26}$.

However, more crystallographic planes are observed for the M1,4RTW and M2,6RTW samples than for the M1,7RTW sample, (see Figures $4 \mathrm{~b}$ and $5 \mathrm{~b}$ ), and at the same time the TC is greater for these samples, as shown in Table 2. In addition, for the M2,6RTW sample the crystallite size is greater than for the M1,4RTW which indicates that, this is a desirable condition for obtaining brushite, but with more energy expenditure. Moreover, to producing phase changes from brushite to HAp is better when carried out on samples obtained at $-1.4 \mathrm{~V}$ and $-1.7 \mathrm{~V}$ because of their lower crystallite size.

\subsection{Post treatments effect}

In accordance with the results previously shown, two post treatments were proposed to determine which promotes HAp phase formation: thermal treatment (TT) and basic treatment (BT).
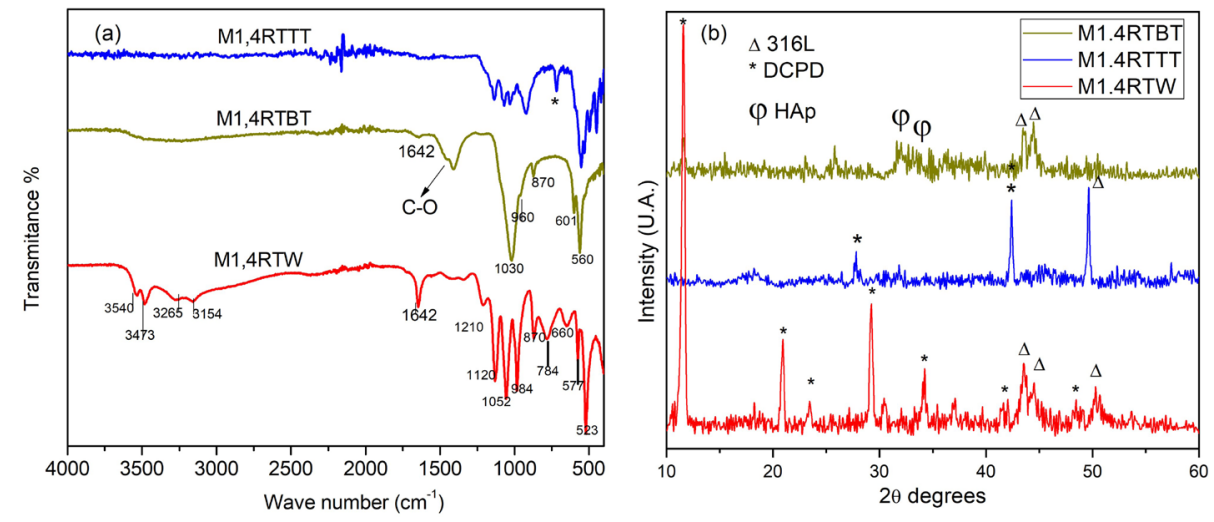

Figure 4. a) FTIR spectra for film growth at $-1.4 \mathrm{~V}$ with and without post treatments. b) XRD pattern for films obtained at $-1.4 \mathrm{~V}$ with and without post treatments.
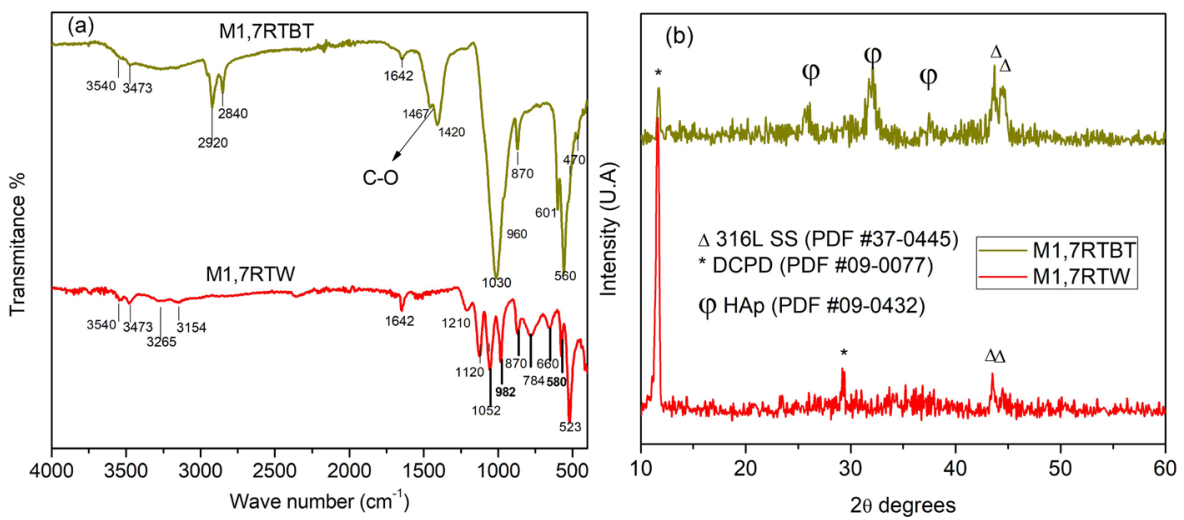

Figure 5. a) FTIR spectra for films obtained at $-1.7 \mathrm{~V}$ with and without basic treatment. b) XRD spectra for M1,7 as-deposited and post treated. 
Table 2. Crystallite size and texture coefficient of electrodeposited films.

\begin{tabular}{ccccc}
\hline Sample & Phase & Plane & Crystallite size $(\mathrm{nm})$ & Texture coefficient \\
\hline M1,4RTW & DCPD & $(020)$ & $0.443 \pm 0.004$ & $2.634 \pm 6 \times 10^{-7}$ \\
\hline M1,7RTW & DCPD & $(020)$ & $0.447 \pm 0.003$ & $1.647 \pm 2 \times 10^{-6}$ \\
\hline M2,6RTW & DCPD & $(020)$ & $1.019 \pm 0.002$ & $2.001 \pm 1 \times 10^{-7}$ \\
\hline M1,4RTBT & HAp & $(112)$ & $0.220 \pm 0.005$ & $0.548 \pm 3 \times 10^{-5}$ \\
\hline M1,7RTBT & HAp & $(112)$ & $1.686+-0.009$ & $1.313 \pm 3 \times 10^{-5}$ \\
\hline
\end{tabular}

Figure 4a shows typical FTIR spectra as deposited and post treated samples obtained at $-1.4 \mathrm{~V}$, meaning the M1,4RTW, M1,4RTBT and M1.4RTTT samples. For M1,4RTBT film, peaks at 560, 601, 960, $1030 \mathrm{~cm}^{-1}$, associated to HAp, are identified; beside the ones associated with DCPD which were observed for M1,4RTW. The peak at $1642 \mathrm{~cm}^{-1}$ associated with $\mathrm{OH}-$ and the $\mathrm{H}_{2} \mathrm{O}$ band at approximately $3500 \mathrm{~cm}^{-1}$ are also identified, while neither the peak in $3565 \mathrm{~cm}^{-1}$ associated to HAp, nor the DCPD peaks in the water band are discriminated. This is indicative that the HAp phase is still amorphous. The presence of carbonates that has been reported and associated, in other works, with the non-structural adsorption of carbonates on the surface of the $\mathrm{HAp}^{35}$, has also been detected in this sample as indicated by the bands in $1455,1420 \mathrm{~cm}^{-1}$ (v3).

On the other hand, for the M1.4RTTT film grown at $-1.4 \mathrm{~V}$ and heat treated, some peaks are observed at 1210, 1120, $984,870,1642,3540$ and $3473 \mathrm{~cm}^{-1}$ which are characteristic of DCPD. In addition, peaks are identified at 1070, 1000, 915 and $530 \mathrm{~cm}^{-1}$ related to OCP. These results suggest that the heat treatment does not favor the formation of the HAP phase, but rather that of OCP. It should be noted that there is a peak at $717 \mathrm{~cm}^{-1}$ which has been labeled in Figure 4a. with an asterisk $(*)$ which corresponds to calcium carbonates as a separate phase ${ }^{36}$.

The phase compositions of the as deposited and posttreated samples were analyzed using XRD spectra and are shown in Figure $4 \mathrm{~b}$. The XRD patterns allow concluding that the main composition of the deposited film was DCPD (brushite) $\left(\mathrm{CaHPO}_{4} \cdot 2 \mathrm{H}_{2} \mathrm{O}\right.$, ICDD \#72-1240) with some peak for the 316L SS substrate. The crystallite size and the TC for this film are shown in Table 2.

The XRD spectrum of the M1,4RTBT sample shows that the DCPD phase is fading, and the HAp phase is beginning to emerge, although still in amorphous form. This can be corroborated with the presence of the diffraction planes (211), (112), (300) that can be obtained from the convolution of the peaks that are in the $2 \theta=32-35^{\circ}$ range. These results agree with those obtained by FTIR: The HAp phase is present in this film and its formation can be attributed to the fact that the basic treatment provides the $\mathrm{OH}$ - groups necessary to complete the synthesis process to pass from the DCPD to the HAp phase. The dissolution of DCPD and the precipitation of the HAp mechanism is proposed by other authors ${ }^{37}$. This mechanism involves the dissolution of the DCPD film followed by the precipitation of the HAP coating, as the next equation describes.

$$
10\left(\mathrm{CaHPO}_{4} \times 2 \mathrm{H}_{2} \mathrm{O}\right)+12 \mathrm{OH}^{-} \rightarrow \mathrm{Ca}_{10}\left(\mathrm{PO}_{4}\right)_{6}(\mathrm{OH})_{2}+6 \mathrm{PO}_{4}{ }^{3-}+30 \mathrm{H}_{2} \mathrm{O}
$$

It is important to note that the HAp is still amorphous as it is corroborated with the crystallite size and the texture coefficient shown in Table 2. The brushite obtained with this potential $(-1.4 \mathrm{~V})$ is more oriented in accordance with TC coefficient, so to change to HAp phase is less efficient than for the sample obtained at $-1.7 \mathrm{~V}$, as will be explained later.

On the other hand, for the M1,4RTTT, some diffraction peak associated to DCPD disappears and others increased, as is shown in Figure 4b. Therefore, based on these results, the HAp phase was not formed in this sample and, as FTIR spectrum suggested, the OCP is presented but in an amorphous phase. One possible mechanism of phase transformation from DCPD to OCP during the thermal treatment has been proposed by Shojai et al. ${ }^{37}$. This mechanism consists of two kinds of dehydration processes: the DCPD dehydration into monetite through losing the structural water molecules, and the dehydration of $\mathrm{HPO}_{4}^{2-}$ ions ${ }^{38}$.

From the results, the basic treatment is preferable over the heat treatment to obtain HAp phase from the electrodeposited DCPD, so for films grown at $-1.7 \mathrm{~V}$ the same analysis was made but only for film with basic post treatment.

For the sample obtained at $-1.7 \mathrm{~V}$, both as-deposited and post-treated, a similar analysis was performed, which is presented below. In Figure 5a, FTIR spectra for M1,7RTW and M1,7RTBT are shown. For M1,7RTW, the characteristic peaks of DCPC in 523, 580, 660, 784, $870,982,1052,1120,1210,1642,3154,3265,3473$ and $3540 \mathrm{~cm}^{-1}$ can be observed. In the M1,7RTBT sample there are some peaks such as $1030,960,601,560 \mathrm{~cm}^{-1}$ and $470 \mathrm{~cm}^{-1}$ which indicate that the HAp phase is formed. Some amount of carbonate phase becoming incorporated into the apatite structure can be seen, as evidenced by the bands at $1467,1420 \mathrm{~cm}^{-1}$ (v3), additionally, two peaks in $2840 \mathrm{~cm}^{-1}$ and $2920 \mathrm{~cm}^{-1}$ associated to $\mathrm{C}-\mathrm{H}$ bonds are presented. The expected sharp peak at $3565 \mathrm{~cm}^{-1}$ is not well resolved in water around $3500 \mathrm{~cm}^{-1}$ indicating that the formed HAp phase might be present but not totally in a crystalline fashion, or the DCPD phase has not completely disappeared.

Figure $5 \mathrm{~b}$ shows the capital $\mathrm{x}$-ray diffraction patterns of the M1,7RTW and M1,7RTBT. The XRD patterns revealed that the main composition of the M1,7RTW film was DCPD with some peaks for the $316 \mathrm{~L}$ stainless steel substrates. For M1,7RTBT sample, the HAp arises as can be seen in peaks at $26^{\circ}, 32^{\circ}$ and $33^{\circ}$, this is corroborated by the FTIR spectra where HAp was identified. The DCPD phase does not completely disappear as the peak at $11^{\circ}$ reveled, which is in accordance with the FTIR spectra. The crystallite size and the texture coefficient of M1,7RTW and M1,7RTBT are shown in Table 2. Obtaining HAp phase with better 

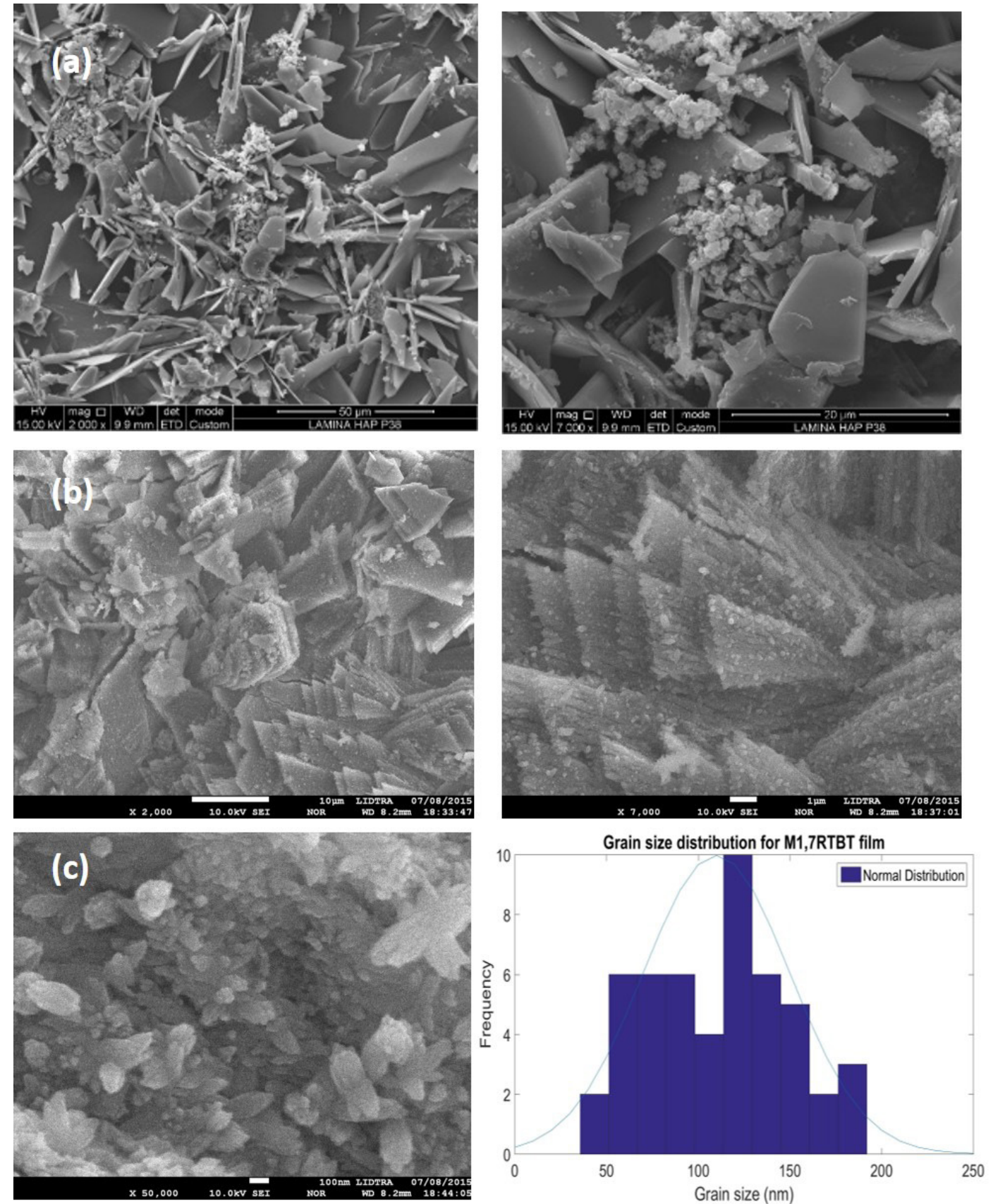

Grain size distribution for M1,7RTBT film

Figure 6. a) SEM images for M1,7RTWwhere brushite phase was identified. b) SEM images for M1,7RTBT where HAp phase was identified. c) Grain size distribution obtained from SEM image of M1,7RTBT film.

crystallinity characteristics than in the M1,4RTBT sample was possible as is corroborated by the diffractograms (see Figures $4 b$ and $5 b$ ).

Films M1,7RTW and M1,7RTBT were analyzed by SEM to ascertain the incidence of basic post treatments over the morphology in the films obtained at $-1.7 \mathrm{~V}$ for which clearer changes in phase were observed. The morphology of films was studied by SEM images and EDS analyses were performed for these films to ascertain the molar $\mathrm{Ca} / \mathrm{P}$ ratio in the films. It is important to consider that molar ratios 
In Figure 6b, a SEM image for M1,7RTBT is presented. The plate-like particles observed in the DCPD phase were transformed into a porous shape in the subsequent stepwise phase, which corresponded to HAp. A grain-like structure associated with HAp phase is observed. This was confirmed in the XRD and FTIR spectra for this film. Some sheet type structure is also observed to a lesser degree, as those associated with the brushite phase have not entirely disappeared as was indicated by XRD analysis. In the EDS analysis, an average ratio of $\mathrm{Ca} / \mathrm{P}=1.65 \pm 0.09$ was found, which is closer to the value reported for HAp.

Figure $6 \mathrm{c}$ shows a statistical analysis of grain size distribution obtained from SEM images of M1,7RTBT film. A normality test was performed using the modified Saphiro Wilk procedure. It was observed that the grain sizes of these films followed a normal distribution, and the average grain size was $110 \pm 40 \mathrm{~nm}$.

Observing some differences in both structures is possible (Figure 6a and 6b); while for brushite phase the sheets are smooth and thin, for HAp they are rough and formed by

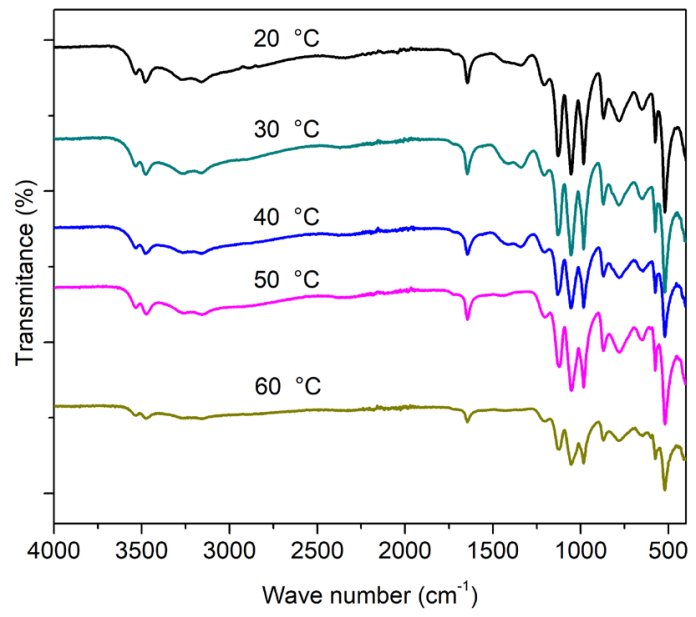

Figure 7. FTIR spectra for M1,4TW a 20, 30, 40, 50 and 60 degrees. grains that can be clearly identified. In the brushite structure, there is grain type morphology over the plates indicating a mixture with another incipient phase may be associated to HAp in the amorphous phase.

\subsection{Electrolytic solution temperature effect}

For this purpose, the growths were conducted using temperatures in the precursor solution to determine if it influenced the coating phase formation. Highlighting that the study was conducted until $60^{\circ} \mathrm{C}$ to avoid damages in the reference electrode is important. Figure 7 shows the FTIR spectra for the films obtained at $-1.4 \mathrm{~V}$ with an electrolyte solution temperature from 20 to $60^{\circ} \mathrm{C}$. There are no important differences between them; the identified phase is brushite for all the employed temperatures. After fitting these spectra, the ratio of intensities of the two most significant bands ( 520 and $1050 \mathrm{~cm}^{-1}$ ) was determined for each sample. Values of 1.30, 1.32, 1.35, 1.33 and 1.31 were obtained for the samples grown at 20 , $30,40,50$ and $60^{\circ} \mathrm{C}$ respectively. Although the values are similar, the sample with the highest ratio is the obtained at $40{ }^{\circ} \mathrm{C}$. This sample was selected to perform the basic treatment to compare with the sample obtained at room temperature.

The FTIR spectra, shown in Figure 8a, evidence that when performing the basic treatment to M1,4TBT samples, vibration modes associated to brushite phase disappear and HAp modes arise. XRD spectra shown in Figure 8b clearly confirms that HAp phase is still amorphous and no better that for the M1,4RTBT or M1,7RTBT obtained at room temperature (Figure $4 \mathrm{~b}$ and $5 \mathrm{~b}$ ).

These results indicate that the use of temperature in the precursor solution does not favor the formation of the HAp crystalline phase nether before nor after BT. In summary, although BT generates the initial HAp formation, there is no difference using temperature in the precursor solution; therefore, using solutions at room temperature due to the lower energy cost is preferred. These results agree with those reported previously where a conventional potentiostat was used ${ }^{26}$.
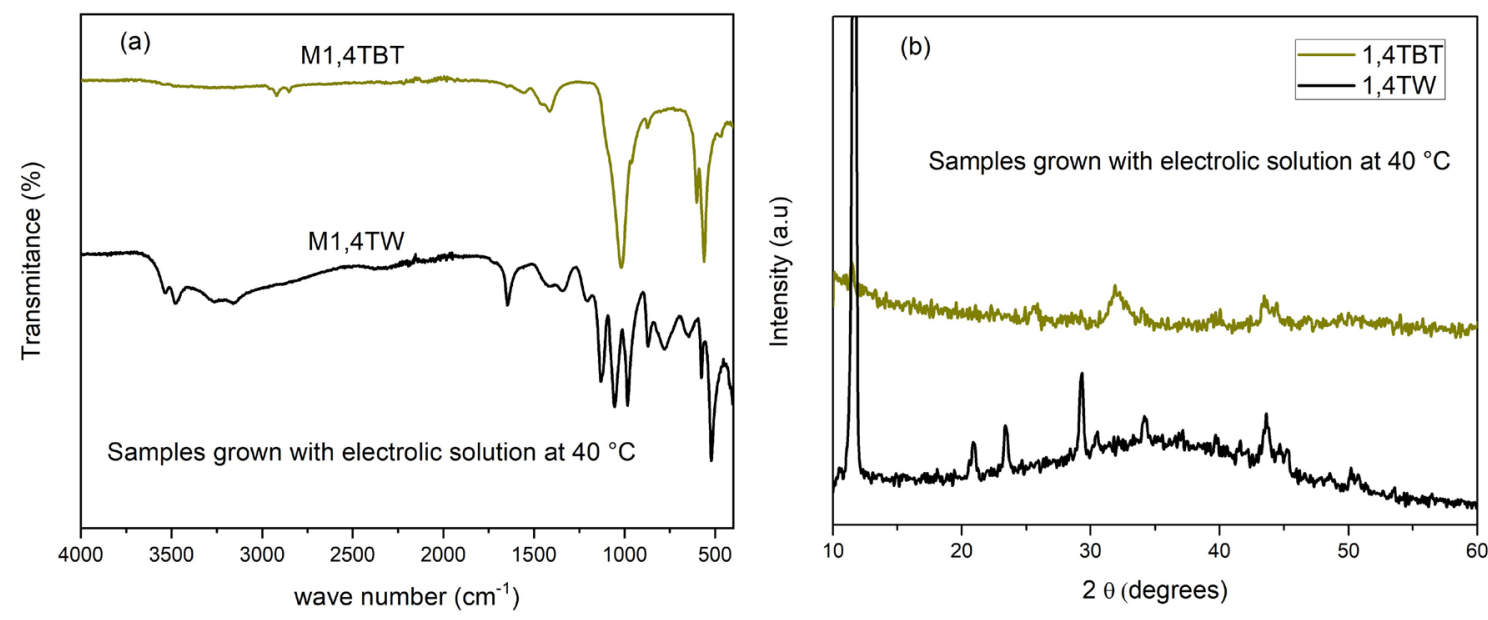

Figure 8. a) FTIR spectra for M1,7TW, M1,7TBT. b) XRD pattern for M1,7TW, 1,7TBT. 


\section{Conclusions}

The cyclic voltammetry curves enable determining the processing parameters, which allowed obtaining $\mathrm{CaP}$ films on $316 \mathrm{~L}$ stainless steel substrates with a potentiostat of the authors' own implementation. These parameters agree with those obtain with a conventional potentiostat.

Films obtained at $-1.4,-1.7$ and $-2.6 \mathrm{~V}$ without further treatment were found to exhibit the DCPD phase. When performing TT, the HAp phase formation is not favored, but OCP phase begins to appear; while with BT, the HAp phase begins to form but in an amorphous state.

The film obtained at $-1.7 \mathrm{~V}$ as deposited led to the formation of DCPD phase. This thermal treated sample favored the amorphous OCP phase, while the basic treated sample led to the formation of HAp with a mixture of DCPD phase. This change of phase may be due to basic treatment provides the necessary OH-groups for HAp phase formation. Additionally, using temperature in the precursor solution was found to not favor the HAp crystal phase formation. This phase appears to be formed but is still amorphous.

The films obtained with the potentiostat of the authors' design and implementation are equivalent to those reported in similar conditions with a conventional potentiostat. Therefore, the potentiostat developed could be used for similar processes with considerable cost savings and with the possibility of continuing to implement more operation modes to allow students and researchers better knowledge of the processes.

\section{Acknowledgements}

The authors give thanks to Colciencias for the young investigator support through the 645 call and to the Universidad Autónoma de Manizales (UAM) for its financial suport to this research throughtout the 503-073 project. The authors thank Gregory Amos who works as a native reviewer at UAM for revising this final manuscript.

\section{References}

1. Beaufils S, Rouillon T, Millet P, Le Bideau J, Weiss P, Chopart $\mathrm{J}-\mathrm{P}$, et al. Synthesis of calcium-deficient hydroxyapatite nanowires and nanotubes performed by template-assisted electrodeposition. Mater Sci Eng C. 2019;98:333-46.

2. Blanda G, Brucato V, Carfi Pavia F, Graco S, Piazza S, Sunseri C, et al. Galvanic deposition and characterization of brushite/ hydroxyapatite coatings on 316L stainless steel. Mater Sci Eng C. 2016;64:93-101.

3. Fekry AM, Azab SM. The development of an innovative nano-coating on the surgical 316 L SS implant and studying the enhancement of corrosion resistance by electrochemical methods using Ibandronate drug. Nano-Structures \& NanoObjects. 2020;21:100411.

4. Hanawa T. Electrodeposition of calcium phosphates, oxides, and molecules to achieve biocompatibility of metals. In: Wandelt K, editor. Encyclopedia of Interfacial Chemistry. San Diego: Elsevier; 2018. p. 129-140.

5. Gu YW, Khor KA, Pan D, Cheang P. Activity of plasma sprayed yttria stabilized zirconia reinforced hydroxyapatite/Ti-6Al-4V composite coatings in simulated body fluid. Biomaterials. 2004;25(16):3177-85.
6. Liu X, He D, Zhou Z, Wang G, Wang Z, Guo X. Effect of postheat treatment on the microstructure of micro-plasma sprayed hydroxyapatite coatings. Surf Coat Tech. 2019;367:225-30.

7. Fornell J, Feng YP, Pellicer E, Suriñach S, Baró MD, Sort J. Mechanical behaviour of brushite and hydroxyapatite coatings electrodeposited on newly developed FeMnSiPd alloys. J Alloys Compd. 2017;729:231-9.

8. Xia W, Fu L, Engqvist H. Critical cracking thickness of calcium phosphates biomimetic coating: verification via a SinghTirumkudulu model. Ceram Int. 2017;43(17):15729-34.

9. Yilmaz B, Pazarceviren AE, Tezcaner A, Evis Z. Historical development of simulated body fluids used in biomedical applications: a review. Microchem J. 2020;155:104713.

10. Ballarre J, López DA, Schreiner WH, Durán A, Ceré SM. Protective hybrid sol-gel coatings containing bioactive particles on surgical grade stainless steel: surface characterization. Appl Surf Sci. 2007;253:7260-4.

11. Ruiz-Aguilar C, Olivares-Pinto U, Aguilar-Reyes EA, LópezJuárez R, Alfonso I. Características de las materias primas usadas por las empresas del sector cerámico del área metropolitana de Cúcuta (Colombia). Bol Soc Esp Ceram Vidr. 2018;57(6):213-20.

12. Lu Y, Dong W, Ding J, Wang W, Wang A. Hydroxyapatite nanomaterials: synthesis, properties, and functional applications. In: Wang A, Wang W, editors. Micro and Nano Technologies, nanomaterials from clay minerals. Amsterdam: Elsevier; 2019. p. $485-536$.

13. Vladescu A, Braic M, Azem F A, Titorencu I, Braic V, Pruna $\mathrm{V}$, et al. Effect of the deposition temperature on corrosion resistance and biocompatibility of the hydroxyapatite coatings. Appl Surf Sci. 2015;354:373-9.

14. Vidal E, Buxadera-Palomero J, Pierre C, Manero JM, Ginebra MP, Cazalbou S, et al. Single-step pulsed electrodeposition of calcium phosphate coatings on titanium for drug delivery. Surf Coat Tech. 2019;358:226-75.

15. Avcu E, Baştan FE, Abdullah HZ, Rehman MAU, Avcu YY, Boccaccini AR. Electrophoretic deposition of chitosan-based composite coatings for biomedical applications: a review. Prog Mater Sci. 2019;103:69-108.

16. Thanh DT, Nam PN, Phuong NT, Que LX, Anh NV, Hoang $\mathrm{T}$, et al. Controlling the electrodeposition, morphology and structure of hydroxyapatite coating on $316 \mathrm{~L}$ stainless steel. Mater Sci Eng C. 2013;33(4):2037-45.

17. Gopi D, Indira J, Kavitha L. A comparative study on the direct and pulsed current electrodeposition of hydroxyapatite coatings on surgical grade stainless steel. Surf Coat Tech. 2012;206(1112):2859-69.

18. Hanawa T. Surface Science and Electrochemistry. In: Wandelt K, editor. Encyclopedia of Interfacial Chemistry. San Diego: Elsevier; 2018.

19. Solla EL, Gonzalez P, Serra J, Chiussi S, Leon B, Lopez JG. Pulsed laser deposition of silicon substituted hydroxyapatite coatings from synthetical and biological sources. Appl Surf Sci. 2007;254(4):1189-93.

20. Mokabber T, Zhou Q, Valkis A, van Rijn P, Pei YT. Mechanical and biological properties of electrodeposited calcium phosphate coatings. Mater Sci Eng C. 2019;100:475-84.

21. Drevet R, Zhukova Y, Dubinskiy S, Kazakbiev A, Naumenko V, Abakumov M, et al. Electrodeposition of cobalt-substituted calcium phosphate coatings on Ti22Nb6Zr alloy for bone implant applications. J Alloys Compd. 2019;793:576-582.

22. Ben-Nissan B. Crystallographic and spectroscopic characterization and morphology of biogenic and synthetic apatites. In: Wise DL, editor. Encyclopedic Handbook of Biomaterials and Bioengineering: part B, applications. New York: Marcel Dekker; 1995, p. 191-221.

23. Eliaz N, Sridhar TM. Electrocrystallization of hydroxyapatite and its dependence on solution conditions. Cryst Growth Des. 2008;8(11):3965-77. 
24. Harun WSW, Asri RIM, Alias J, Zulkifli FH, Kadirgama K, Ghani SAC, et al. A comprehensive review of hydroxyapatitebased coatings adhesion on metallic biomaterials. Ceram Int. 2018;44(2):1250-68.

25. Wang MC, Chen HT, Shih WJ, Chang HF, Hon MH, Hung IM. Crystalline size, microstructure and biocompatibility of hydroxyapatite nanopowders by hydrolysis of calcium hydrogen phosphate dehydrate (DCPD). Ceram Int. 2015;41(2):2999-3008.

26. Jiménez-García FN, Giraldo-Torres LR, Segura-Giraldo B, Giraldo-Betancur AL, Muñoz-Saldaña J. Effect of growing conditions and post treatments on calcium phosphate films obtained by electrode position. J Surf Sci Tech 2019;35(12):67-76.

27. Manso M, Jiménez C, Morant C, Herrero P, Martinez JM. Electrodeposition of hydroxyapatite coatings in basic conditions. Biomaterials. 2000;21(17):1755-61.

28. Drevet R, Fauré J, Benhayoune H. Structural and morphological study of electrodeposited calcium phosphate materials submitted to thermal treatment. Mater Lett. 2017;209:27-31.

29. Giraldo-Torres LR, Segura-Giraldo B, Jiménez-García FN. Prototipo de potenciostato con aplicaciones en procesos electroquímicos. Entre Ciencia e Ingenieria. 2016;10(19):61-69.

30. Kandori K, Mizumoto S, Toshima S, Fukusumi M, Morisada Y. Effects of heat treatment of calcium hydroxyapatite particles on the protein adsorption. J Phys Chem B. 2009;113:11016-22.

31. Kannan MB. Electrochemical deposition of calcium phosphates on magnesium and its alloys for improved biodegradation performance: a review. Surf Coat Tech. 2016;301:36-41.
32. Petrov I, Šoptrajanov B, Fuson N, Lawson JR. Infra-red investigation of dicalcium phosphates. Spectrochim Acta A. Molecular Spectroscopy. 1967;23(10):2637-46.

33. Falk $\mathrm{M}$. The frequency of the $\mathrm{H}-\mathrm{O}-\mathrm{H}$ bending fundamental in solids and liquids. Spectrochim Acta A. Molecular Spectroscopy. 1984;40(1):43-8.

34. Gopi D, Prakash VC, Kavitha L, Kannan S, Bhalaji PR, Shinyjoy E, et al. A facile electrodeposition of hydroxyapatite onto borate passivated surgical grade stainless steel. Corros Sci. 2011;53(6):2328-34.

35. Kamalanathan P, Ramesh S, Bang L, Niakan A, Tan C, Purbolaksono J, et al. Synthesis and sintering of hydroxyapatite derived fromeggshells as a calcium precurso. Ceram Int. 2014;40(10):16349-59.

36. LeGeros RZ, LeGeros JP, Trautz OR, Klein E. Spectral properties of carbonate in carbonate-contening apatites. Appl Spectrosc. 1970;7:3-12.

37. Sadat-Shojai M, Khorasani MT, Jamshidi A. Hydrothermal processing of hydroxyapatite nanoparticles: a Taguchi experimental design approach. J Cryst Growth. 2012;361:73-84.

38. Sridhar TM, Mudali UK, Subbaiyan M. Preparation and characterisation of electrophoretically deposited hydroxyapatite coatings on type 316L stainless steel. Corros Sci. 2003;45(2):237-52.

39. Dorozhkin S. Calcium orthophosphates: applied in Nature, Biology and Medicine. Materials. 2012;2(2):399-498.

40. Arifuzzaman SM, Rohani S. Experimental study of brushite precipitation. J Cryst Growth. 2004;267(3-4):624-34. 